\title{
Restoring Perivascular Adipose Tissue Function in Obesity Using Exercise
}

\author{
Sophie N Saxton ${ }^{1,2} \cdot$ Lauren K Toms $^{1} \cdot$ Robert G Aldous $^{3} \cdot$ Sarah B Withers $^{1,2,4} \cdot$ Jacqueline Ohanian $^{1}$. \\ Anthony M Heagerty ${ }^{1,2,5}$
}

Accepted: 21 December 2020 / Published online: 9 March 2021

(C) The Author(s) 2020

\begin{abstract}
Purpose Perivascular adipose tissue (PVAT) exerts an anti-contractile effect which is vital in regulating vascular tone. This effect is mediated via sympathetic nervous stimulation of PVAT by a mechanism which involves noradrenaline uptake through organic cation transporter 3 (OCT3) and $\beta_{3}$-adrenoceptor-mediated adiponectin release. In obesity, autonomic dysfunction occurs, which may result in a loss of PVAT function and subsequent vascular disease. Accordingly, we have investigated abnormalities in obese PVAT, and the potential for exercise in restoring function.

Methods Vascular contractility to electrical field stimulation (EFS) was assessed ex vivo in the presence of pharmacological tools in \pm PVAT vessels from obese and exercised obese mice. Immunohistochemistry was used to detect changes in expression of $\beta_{3}$-adrenoceptors, OCT3 and tumour necrosis factor- $\alpha$ (TNF $\left.\alpha\right)$ in PVAT.

Results High fat feeding induced hypertension, hyperglycaemia, and hyperinsulinaemia, which was reversed using exercise, independent of weight loss. Obesity induced a loss of the PVAT anti-contractile effect, which could not be restored via $\beta_{3}$ adrenoceptor activation. Moreover, adiponectin no longer exerts vasodilation. Additionally, exercise reversed PVAT dysfunction in obesity by reducing inflammation of PVAT and increasing $\beta_{3}$-adrenoceptor and OCT3 expression, which were downregulated in obesity. Furthermore, the vasodilator effects of adiponectin were restored.

Conclusion Loss of neutrally mediated PVAT anti-contractile function in obesity will contribute to the development of hypertension and type II diabetes. Exercise training will restore function and treat the vascular complications of obesity.
\end{abstract}

Keywords Adipocytes · Adrenoceptors · Obesity $\cdot$ Exercise $\cdot$ Sympathetic nervous system

Abbreviations

EFS Electrical field stimulation

KPSS High potassium physiological salt solution

Anthony M Heagerty

tony.heagerty@manchester.ac.uk

1 Division of Cardiovascular Sciences, University of Manchester, Manchester, UK

2 The Lydia Becker Institute of Immunology \& Inflammation, University of Manchester, Manchester, UK

3 King's College Hospital, London, UK

4 School of Science, Engineering and Environment, University of Salford, Salford, UK

5 Division of Cardiovascular Sciences, Manchester Academic Health Science Centre, Core Technology Facility (3rd floor), 46 Grafton Street, Manchester M13 9NT, UK

\begin{tabular}{|c|c|}
\hline L-NMMA & $\mathrm{L}-\mathrm{N}^{\mathrm{G}}$-monomethyl arginine citrate \\
\hline NA & Noradrenaline \\
\hline NOS & Nitric oxide synthase \\
\hline OCT & Organic cation transporter \\
\hline PSS & Physiological salt solution \\
\hline PVAT & Perivascular adipose tissue \\
\hline $\mathrm{TNF} \alpha$ & Tumour necrosis factor alpha \\
\hline
\end{tabular}

\section{Introduction}

Perivascular adipose tissue (PVAT) is a highly metabolically active tissue which surrounds the majority of blood vessels and contributes to the modulation of vascular tone [1-3]. Previously, we have presented evidence that the mechanisms of this effect are mediated via the sympathetic nervous system and are two-fold [4]; first, sympathetic nerve-derived noradrenaline (NA) activates adipocyte $\beta_{3}$-adrenoceptors, which 
triggers the release of the vasodilator adiponectin. Second, excess NA is sequestered by adipocytes via organic cation transporter 3 (OCT3). In obesity, PVAT function is lost, which may contribute to development of metabolic syndrome [5-7]. However, the mechanisms behind this loss of function are unclear.

It is well known that in obesity, pathological over-activity of the sympathetic nervous system occurs $[8,9]$. Cardiac $\beta$ adrenoceptors become desensitised in heart failure, as a result of sympathetic nerve over-activity [10]. It is possible that in PVAT, increased sympathetic activity could result in a desensitisation of $\beta_{3}$-adrenoceptors, leading to reduced adiponectin release. Bioavailability of adiponectin has already been demonstrated to be reduced in human obesity [11], hypertension [12], and type II diabetes [13].

In obesity, PVAT morphology changes, and adipocyte size and number increase. However, there is no increase in blood supply, leading to hypoxia and chronic inflammation $[14,15]$. By subjecting human and mouse mesenteric arteries to hypoxia, the loss of the PVAT anti-contractile effect can be replicated $[6,16]$. There is substantial evidence for the role of inflammation in the loss of PVAT function [17]. Hypoxiainduced loss of anti-contractile function is prevented in the absence of macrophages from the PVAT [16]. Moreover, cytokine antagonists can be used to rescue hypoxia-induced damage to PVAT function [6]. This suggests that hypoxia induces an inflammatory response involving classical macrophage activation, leading to the release of cytokines into the local environment, which damages the adipocytes. Furthermore, hypoxia-induced damage can also be rescued using free radical scavengers $[6,16,18]$, illustrating that hypoxia causes oxidative stress, which can ultimately cause damage to the surrounding environment.

The role of adiponectin in the inflammatory response may contribute to insulin insensitivity. Adiponectin is an inhibitor of the cytokine tumour necrosis factor- $\alpha \mathrm{TNF} \alpha$ ), which inhibits insulin signalling [19-22]. Therefore, reduced levels of adiponectin will increase TNF $\alpha$-mediated inhibition of insulin signalling. Furthermore, TNF $\alpha$ expression is increased in obesity [22], further inhibiting the vasodilator effects of insulin in skeletal muscle, reducing blood flow and glucose uptake, and leading to type-II diabetes.

Sympathetic nerves play a role in recruiting inflammatory mediators, and a number of studies have demonstrated that exercise, which is considered to be healthy sympathetic stimulation, can reduce inflammation in obesity [23-26]. In a study of inflammation in skeletal muscle, forced interval training in high fat-fed mice significantly reduced macrophage infiltration [23]. Interestingly, these effects were independent of weight loss. In a similar study using forced exercise, macrophage infiltration and inflammatory cytokine expression were reduced in the adipocytes of epididymal fat pads of obese exercised trained mice, again independent of weight loss [25]. Another study using obese mice provided with a wheel for voluntary exercise [24] demonstrated significant improvements in insulin-sensitivity, glucose tolerance, and reduced total body fat mass and exhibited a significant reduction in inflammatory cytokine expression including TNF $\alpha$. In diabetic obese human patients, exercise has been shown to reduce TNF $\alpha$ and interleukin- 6 expression in subcutaneous adipose [27]. The results of these studies could be applied to reduce macrophage infiltration and inflammatory cytokine expression in PVAT surrounding resistance arteries, reversing obesity-induced damage to PVAT, and alleviating the vascular complications of obesity, i.e., hypertension and diabetes.

The beneficial effects of exercise on brown adipose tissue function surrounding the aorta has been well documented [28-31]; however, the effects of exercise on white mesenteric PVAT function and small resistance arteries have not yet been characterised. Previous weight loss studies such as bariatric surgery [32], and caloric restriction [33] have shown success in restoring PVAT function in obesity. In addition, pharmacological intervention to increase endothelial nitric oxide synthase (NOS) phosphorylation in obesity successfully restored function of aortic PVAT [34]. Alongside improvements in PVAT function, these studies also demonstrated improvements in insulin sensitivity and blood pressure, highlighting the importance of restoring PVAT function to treat the vascular complications of obesity.

The present study was designed to examine the mechanisms of PVAT dysfunction in obesity and the potential for a significant lifestyle intervention in restoring function. We tested the hypothesis that a loss of PVAT function in obesity can be reversed via exercise. We anticipate that in obesity, PVAT becomes inflamed, and expression of $\beta_{3^{-}}$adrenoceptors and OCT3 are reduced. These changes in the PVAT environment will be reversed by exercise. In addition, we hypothesise that the resultant symptoms of metabolic syndrome in obesity will be alleviated by exercise.

\section{Materials and Methods}

\section{Animal Care and Ex Vivo Measurements}

All experiments were performed in accordance with the appropriate Home Office project licence and complied with the UK Animal (Scientific Procedures) Act 1986. Male C57BL/6j mice were randomly assigned to three groups; control, obese, and exercised obese (see below) and aged until 18-20 weeks. Animals were housed under a 12-h light/12-h dark cycle and provided with food and water ad libitum. The body weights of all groups were recorded every 2 weeks from 8 weeks of age. Mice were fasted overnight and sacrificed using $\mathrm{CO}_{2}$ asphyxiation. Prior to sacrifice, blood pressure was recorded in 
conscious, restrained animals using the CODA tail cuff blood pressure monitoring system (Kent Scientific, USA). Immediately after sacrifice mixed blood samples were collected by severing the thoracic aorta. Blood glucose concentration was measured immediately using an automatic blood glucose system (Contour, Bayer Consumer Care AG, Basel, Switzerland). Following euthanisation, the mesentery was exposed and removed. Epididymal fat pads, hearts, and kidneys were collected and weighed.

\section{Control Mice}

Control mice were fed a standard chow diet ad libitum $(7.42 \%$ fat, cat no. BK001, SDS Diets, UK) until they were euthanised at $18-20$ weeks old $(n=20)$.

\section{Obese Mice: Diet-Induced Obesity}

Male C57BL/6j mice (Harlan Laboratories, UK) were purchased at 6 weeks old and allowed a 2-week acclimatisation period before being placed on a $60 \% \mathrm{kcal}$ from fat diet (cat no. 824054, SDS Diets, UK) ad libitum for 10-12 weeks and euthanised at $18-20$ weeks $(n=44)$. A $10-25 \%$ increase in body weight as compared with age-matched controls is considered as moderate obesity in rodents [35]; therefore, to eliminate mice which may be resistant to obesity, mice with less than a $10 \%$ increase in body weight as compared with healthy controls were excluded from this study.

\section{Exercised Obese Mice}

For exercised obese mice, male C57BL/6j mice followed the diet-induced obesity protocol as described above. At week five, forced swim training commenced. Mice were initially exercised for 15 min once a day, and the duration of exercise increased in daily increments of 15 min until reaching a final duration of $60 \mathrm{~min}$. From week six, mice were exercised five times per week. Mice were swum in tanks with a surface area of $2,500 \mathrm{~cm}^{2}$ and a depth of $35 \mathrm{~cm}$. Water temperature was maintained at $32-35^{\circ} \mathrm{C}$. At the end of the exercise, mice were carefully towel dried and kept in a drying enclosure at $30^{\circ} \mathrm{C}$ for 1 hour. All mice were able to complete this training. This exercise regime was continued until mice were aged $18-$ 20 weeks before euthanising [36] $(n=20)$.

For the exercised obese model, there were two additional control groups. The first group was a diet-induced obesity group, which were high fat fed as described above, and were euthanised after 5 weeks (the time point at which exercised groups commenced training) to examine mouse phenotype and PVAT function at this time point $(n=10$; Supplementary Figure 1). This control was used to determine that PVAT function is already lost by this time point, resulting in hypertension and hyperglycaemia, confirming that exercise reverses dysfunction as opposed to preventing dysfunction. Another control group of mice were maintained on a standard chow diet and exercised along the same time line as the obese exercised group; five times per week for $60 \mathrm{~min}(n=8$; Supplementary Figure 2). There were no changes in PVAT function or the phenotype of these mice, eliminating the possibility that the stress of water exposure and/or exercise is the cause for any changes in exercised obese mice. For all animal model timelines, see Supplementary Figure 3.

\section{Blood Plasma Studies}

Collected blood samples were centrifuged at $3000 \times g$ for $10 \mathrm{~min}$ at $4{ }^{\circ} \mathrm{C}$ to separate plasma. Plasma samples were then stored at $-80^{\circ} \mathrm{C}$ until required. Concentration of plasma NA, adiponectin, and insulin was measured using commercially available ELISA kits according to manufacturer's instructions (Table 1). All samples and standards were measured in duplicate, and the optical density of the zero standard was subtracted from each value. Standard curves were fitted using non-linear regression analysis with a sigmoidal four parameter logistic curve to interpolate values.

\section{Wire Myography}

Second-order mesenteric arteries were prepared as previously described [37]. Arterial segments $(<250 \mu \mathrm{m})$ with PVAT removed or left intact were dissected in ice cold physiological salt solution (PSS, in mmol L ${ }^{-1}$; $\mathrm{NaCl}, 119 ; \mathrm{KCl}, 4.7 ; \mathrm{MgSO}_{4}$, 1.17; $\mathrm{NaHCO}_{3}, 25 ; \mathrm{KH}_{2} \mathrm{PO}_{4}, 1.17$; EDTA, 0.03; glucose, 5.5; and $\left.\mathrm{CaCl}_{2}, 1.6\right)$ and were mounted on $40-\mu \mathrm{m}$ diameter wires in a wire myograph (Danish MyoTech, Denmark). Arteries were allowed to equilibrate for $30 \mathrm{~min}$ at $37{ }^{\circ} \mathrm{C}$ in PSS bubbled with $95 \%$ air/5\% $\mathrm{CO}_{2}$ to maintain a $\mathrm{pH}$ of 7.4 . Following equilibration, vessel starting tension was standardised using a standard normalisation procedure [38]. Vessels were left for a further 30-min equilibration period. To test vessel viability, vessels were challenged with high $\mathrm{K}^{+}$PSS (KPSS, in mmol $\mathrm{L}^{-1} ; \mathrm{NaCl}, 63.7 ; \mathrm{KCl}, 60 ; \mathrm{MgSO}_{4}, 1.17 ; \mathrm{NaHCO}_{3}, 25$; $\mathrm{KH}_{2} \mathrm{PO}_{4}, 1.17 ; \mathrm{K}_{2}$ EDTA, 0.03; glucose, 5.5; and $\mathrm{CaCl}_{2}$, 1.6). Vessels were stimulated using an electrical field stimulation protocol over a frequency range of $0.1-30 \mathrm{~Hz}(20 \mathrm{~V}, 4 \mathrm{~s}$ stimulus duration, $0.2 \mathrm{~ms}$ pulse duration) [37]. Stimulation was conducted using a Danish MyoTech CS4 stimulator. LabChart 7 acquisition software (RRID:SCR_001620, AD Instruments, UK) was used to continuously record responses.

\section{Pharmacological Assessment}

Previously published pharmacological assessment which has been conducted in control vessels were repeated in obese and exercised obese vessels in this study [37]. $\beta_{3^{-}}$ adrenoceptor agonists and antagonists were used to 
Table 1 Commercially available ELISA kits used to measure plasma NA, adiponectin, and insulin

\begin{tabular}{lllr}
\hline Antigen & Name of kit & Supplier & Catalogue no. \\
\hline Adiponectin & Adiponectin mouse ELISA kit & Life Technologies Ltd & KMP0041 \\
Insulin & Insulin mouse ELISA kit & Invitrogen & EMAT supernatant-1 in 100 \\
Noradrenaline & NA/NE ELISA kit & Elabscience & E-EL-0047 in 2 \\
\hline
\end{tabular}

delineate their role in mediating the vascular response to EFS in the presence or absence of PVAT; following the first EFS stimulation, $\beta_{3}$-adrenoceptor agonist $\mathrm{CL}$ $316,243(10 \mu \mathrm{M})$ or $\beta_{3}$-adrenoceptor antagonist SR59230A (1 $\mu \mathrm{M})$ was added to \pm PVAT vessels and incubated for $30 \mathrm{~min}$, before re-stimulating the vessels. The effects of globular adiponectin $(5 \mu \mathrm{g} / \mathrm{ml})$ were tested on only -PVAT vessels. Vessels were stimulated once and allowed to recover for $15 \mathrm{~min}$ before adding adiponectin. The adiponectin was incubated for $5 \mathrm{~min}$ before repeating the EFS protocol.

To examine the role of nitric oxide and NA transport, a third arterial preparation was used whereby a section of exogenous PVAT was suspended above a clean artery (Ref no. [37] for illustration of all arterial preparations). This allowed the removal of PVAT for incubation with OCT3 inhibitor corticosterone $(100 \mu \mathrm{M})$, and eliminated interference with NA uptake within the artery.

Time controls were conducted alongside all experiments to ensure that any change in vascular responsiveness was not a time effect (data not shown).

\section{Adiponectin Assay}

To quantify adiponectin secretion from obese PVAT compared with healthy controls, PVAT was collected from the mesenteric bed of control and obese mice and weighed. As previously described [4], harvested PVAT was incubated in PSS for 30 min bubbled with $95 \%$ air $/ 5 \% \mathrm{CO}_{2}$ before stimulating using EFS at $10 \mathrm{~Hz}$ for $4 \mathrm{~s}(20 \mathrm{~V}$, pulse duration $0.2 \mathrm{~ms}$ ). The supernatant was collected and stored at $80{ }^{\circ} \mathrm{C}$. An adiponectin ELISA kit (Table 1) was used to quantify adiponectin secretion according to manufacturer instructions. Concentration was determined through measurement of absorbance using a plate reader (BioTek, Northstar Scientific, UK) at $450 \mathrm{~nm}$ and was calculated per $100 \mathrm{mg}$ of PVAT to account for variation in the amount of PVAT collected from each mesenteric bed.

\section{Drug Preparations}

CL-316,243, and SR59230A were obtained from Tocris biosciences (R\&D systems, UK) and dissolved in PSS.
Recombinant mouse globular adiponectin was obtained from

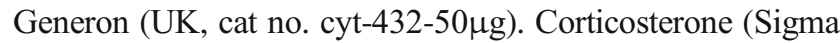
Aldrich, UK) was dissolved in $100 \%$ ethanol. Vehicle controls confirm no effect of $100 \%$ ethanol (data not shown).

\section{Immunohistochemistry}

$\beta_{3}$-adrenoceptor, OCT3, and tumour necrosis factor alpha $(\mathrm{TNF} \alpha)$ expression was assessed in control, obese, and exercised obese PVAT by immunohistochemistry [37]. In brief, sections of PVAT from control, obese, and exercised obese mice embedded in KP-CryoCompound (Klinipath BV, The Netherlands) and $12-\mu \mathrm{m}$ sections were made using a cryostat. Heat-induced antigen retrieval followed by blocking of exogenous peroxide activity was performed. Sections were blocked with goat serum before incubation with primary antibodies for $\beta_{3}$ adrenoceptors $(10 \mu \mathrm{g} / \mathrm{ml}$, Abcam, Cambridge, UK, cat no. ab59685, RRID:AB_2225531), OCT3 (10 $\mu \mathrm{g} / \mathrm{ml}$, Sigma Aldrich, UK, cat no. A V44026, RRID:AB_1854770), or TNF $\alpha(10 \mu \mathrm{g} / \mathrm{ml}$, Abcam, Cambridge, UK, cat no. ab6671, RRID:AB_305641) overnight at $4{ }^{\circ} \mathrm{C}$. Slides were then incubated with a biotinylated goat anti-rabbit secondary antibody $(2 \mu \mathrm{g} / \mathrm{ml}$, Abcam, UK, cat no. ab6720, RRID:AB_954902) for 1 hour at room temperature before addition of vectastain avidin-biotin complex (Vector Laboratories, UK) and 3,3'-diaminobenzidine solution (Vector Laboratories, UK) for detection of antibody binding. Images were captured using a colour camera (Leica DFC450, Leica Microsystems, Germany) mounted on a microscope (Leica DM5000, Leica Microsystems, Germany).

Mouse kidney was used as a positive control, and negative controls were conducted using samples incubated with phosphate buffered saline in place of the primary antibody. Controls are provided in Supplementary Figure 4.

\section{Statistical Analysis}

Data are expressed as the mean \pm SEM. All statistical analysis was performed using GraphPad Prism v7 (RRID:SCR_002798, GraphPad Software USA). $P$ values $<0.05$ were considered statistically significant. Normal 
distribution was confirmed using the Shapiro-Wilk normality test, supported by Skewness and Kurtosis coefficients (using an acceptable range of \pm 2 ).

\section{Phenotype Data}

Differences in mouse phenotype measures including blood pressure, blood glucose, organ weights, and plasma ELISA data were analysed using a one-way analysis of variance (ANOVA) followed by a Tukey post hoc test to compare individual groups. For body weight progression, differences were tested using a two-way ANOVA. A minimum sample size of 20 was used for each group. For blood pressure, the average of the 10 measurement cycles was used from each mouse [39].

\section{Wire Myography}

Contractile responses were normalised to the maximum contraction elicited with KPSS, as consistent with other studies $[6,16,37,40]$ and are expressed as a percentage. Differences between the frequency-response curves of \pm PVAT vessels were tested using a two-way ANOVA, with a Bonferroni post-hoc test. Before and after treatments within the same vessel types were compared using a repeated-measures ANOVA, again followed by a Bonferroni post-hoc test. Due to expense, an $n$ of 4 was used for exogenous adiponectin experiments. For all other experiments an $\mathrm{n}$ of 8 was used.

\section{Immunohistochemistry}

Quantitative analysis of immunostaining was performed using ImageJ (RRID:SCR_003070, v1.47, NIH, USA). Images were taken from five fields of view per mouse. The intensities of staining for $\beta_{3}$-adrenoceptors and OCT3, which were localised to adipocyte membranes, were quantified within/around five arbitrarily selected adipocytes, i.e., staining intensity per adipocyte, as opposed to using a set sized area for staining. This was to account for changes in adipocyte size. TNF $\alpha$ staining was quantified within the whole field of view. Correlation of adipocyte area and intensity of adipocyte membrane staining were assessed to confirm that changes in intensity were not due to changes in adipocyte size (See Supplementary data 5). Statistical differences were analysed using a oneway ANOVA followed by a post hoc Tukey's test to compare individual groups. Sample sizes of five were used for each group.

\section{Results}

\section{High Fat Feeding Resulted in Metabolic Syndrome and Autonomic Dysfunction, which Is Reversed Using Exercise}

Obesity was established in C57BL/6j mice by high fat feeding for 10-12 weeks. High fat feeding resulted in a significant increase in body weight in both obese and exercised obese mouse groups (Fig. 1a, control $n=20$, obese $n=44$, exercised $n=20$. Control vs obese $P<0.0001$, control vs exercised obese $P<0.0001$ ). The difference in body weight became significant after 4 weeks of high fat feeding $(P<0.01)$. At week 6 , the exercised obese group commenced swimming. This group exhibited no further significant increases in weight gain; however, these mice did not lose any weight. To confirm that changes in weight were due to increases in fat depots and not muscle mass, epididymal fat pads were removed and weighed (Fig. 1b, control $n=20$, obese $n=$ 44 , exercised obese $n=20$ ). High fat feeding resulted in a significant increase in fat depots in both obese and exercised obese groups (control vs obese $P<0.0001$, obese vs exercised obese $P<0.01$, control vs exercised obese $P<0.0001$ ).

High fat feeding resulted in significant elevations in both systolic and diastolic blood pressures in the obese group; however, in the exercised obese group, blood pressure was comparable with healthy control mice (Fig. 1c, $n=20$ all groups. Both systolic and diastolic: control vs obese $P<0.01$, obese vs exercised obese $P<0.01$, control vs exercised obese $P>0.05$ ). There were no changes in heart or kidneys weights (Supplementary Figure 6) indicating that hypertension cannot be attributed to cardiac hypertrophy or kidney dysfunction. In a similar fashion to blood pressure, high fat feeding resulted in hyperglycaemia in the obese group; however, following exercise, blood glucose concentration normalised (Fig. 1c, control $n=20$, obese $n=44$, exercised obese $n=20$. Control vs obese $P<0.01$, obese vs exercised obese $P<0.01$, control vs exercised obese $P>0.05$ ).

ELISA kits were used to measure plasma insulin (Fig. 1e) and NA (Fig. 1f) (control and obese groups $n=22$, exercised obese $n=20$ ). Plasma insulin was significantly increased in obesity, which combined with hyperglycaemia indicating possible type II diabetes. Insulin was reduced in the exercised obese group (control vs obese $P<0.0001$, obese vs exercised obese $P<0.0001$, control vs exercised obese $P>0.05$ ), and plasma NA was significantly reduced in obesity, indicating autonomic dysfunction. In exercise, NA was restored to control levels (control vs obese $P<0.0001$, obese vs exercised obese $P<0.0001$, control vs exercised obese $P>0.05$ ).

Expression of the inflammatory cytokine TNF $\alpha$ was examined using immunohistochemistry in sections of mesenteric PVAT from control, obese, and exercised obese mice (Fig. $2 ; n=5$ all groups). In obese mice, staining intensity of 
a

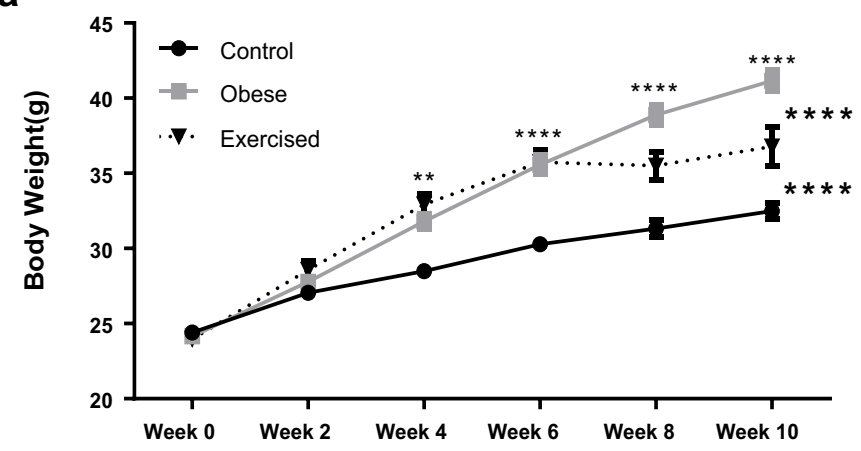

C

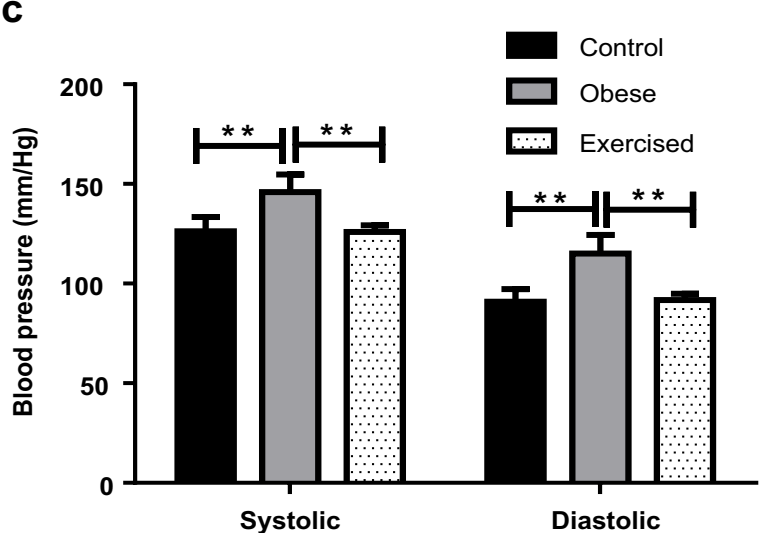

e

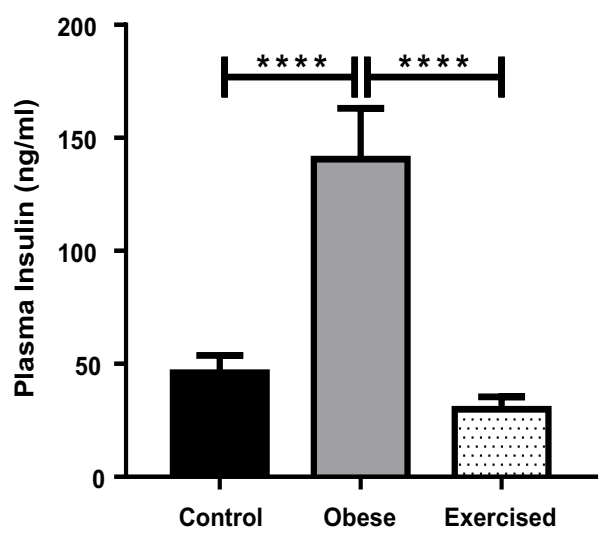

Fig. 1 High fat feeding results in obesity and metabolic syndrome which is reversed by exercise. a Body weights of control, obese, and exercised obese mice were recorded every 2 weeks (control $n=20$, obese $n=44$, exercised $n=20$ ). b Following sacrifice, epididymal fat pads were removed and weighed (control $n=20$, obese $n=44$, exercised $n=20$ ). c Prior to sacrifice, blood pressure was recorded using a CODA tail cuff system ( $n=20$ all groups). d Following sacrifice, blood was collected and

TNF $\alpha$ in PVAT was significantly increased compared with controls $(P<0.001)$. In obese exercised mice, expression of $\mathrm{TNF} \alpha$ was significantly reduced as compared with both obese $(P<0.0001)$ and control mice $(P<0.05)$ (for positive and negative controls, see Supplementary Figure 4), suggesting that exercise has substantial beneficial effects alleviating inflammation in obesity.
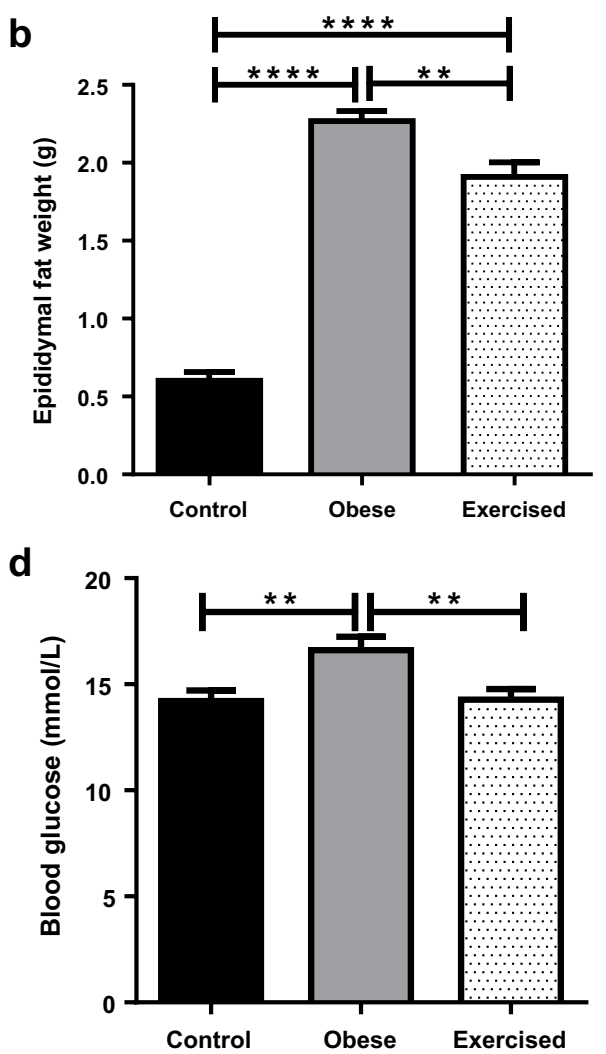

$\mathbf{f}$

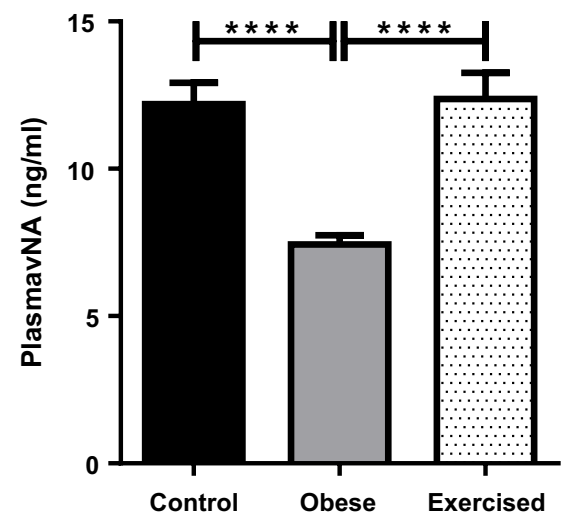

glucose concentration was measured using an automatic monitor (control $n=20$, obese $n=44$, exercised $n=20$ ). Blood was collected and centrifuged to separate plasma. Plasma concentrations of insulin (e) and NA (f) were measured using ELISA kits (control $n=22$, obese $n=22$, exercised $n=20)$. Data shown are mean \pm SEM $(* * P<0.01$, $* * * * P<0.0001)$ (NA: noradrenaline)

\section{Exercise Successfully Restored PVAT Function in Obesity}

To examine the effects of obesity on sympathetic nerve function in PVAT, EFS profiles were generated in mesenteric resistance arteries from obese mice $(0.1-30 \mathrm{~Hz}, 20 \mathrm{~V}, 0.2 \mathrm{~ms}$ pulse duration, $4 \mathrm{~s}$ train duration). In obese mice, there was no 


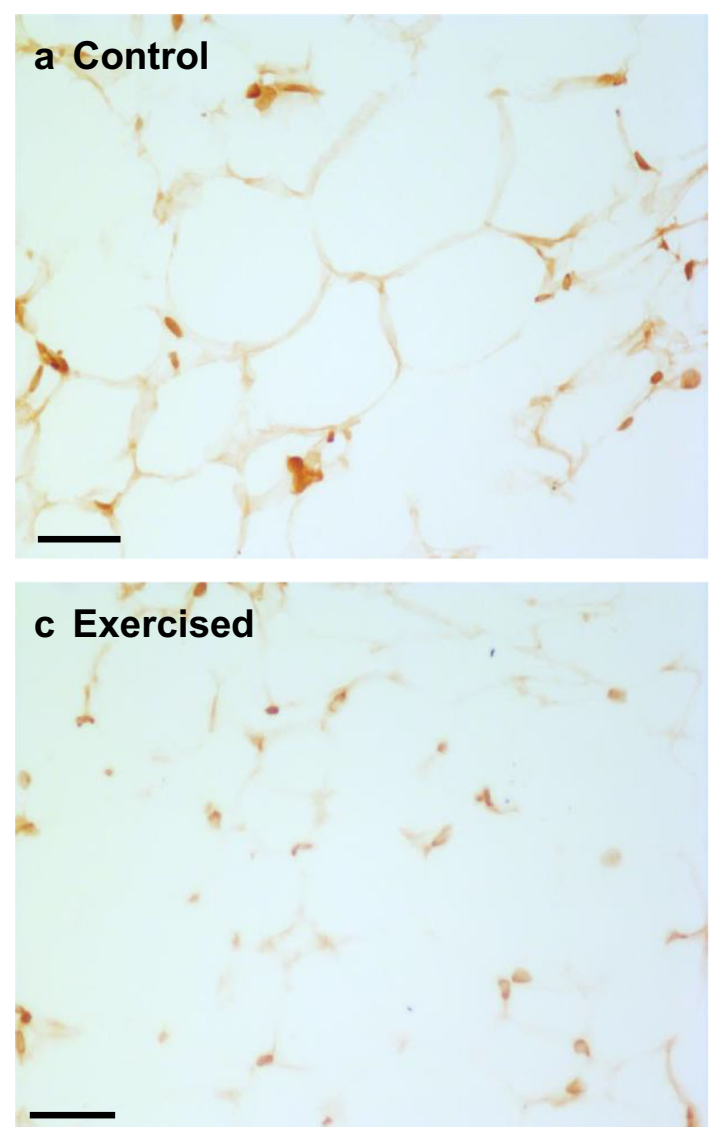

Fig. 2 Exercise reduced inflammation in obesity. Sections of mouse mesenteric PVAT from control mice (a), obese (b), and exercised obese mice (c) were stained for TNF $\alpha$. Scale bar represents $50 \mu \mathrm{m}$. Staining intensity in the whole field of view was quantified (d). Data shown are

significant difference between -PVAT and +PVAT vessels (Fig. 3a; $P>0.05, n=8$ ). Therefore, electrical activation of sympathetic nerves in obese PVAT no longer elicits an anticontractile effect. However, electrical activation of sympathetic nerves in exercised obese PVAT elicited a significant anticontractile effect (Fig. 3b; $P<0.0001, n=8$ ), indicating that exercise has restored PVAT function.

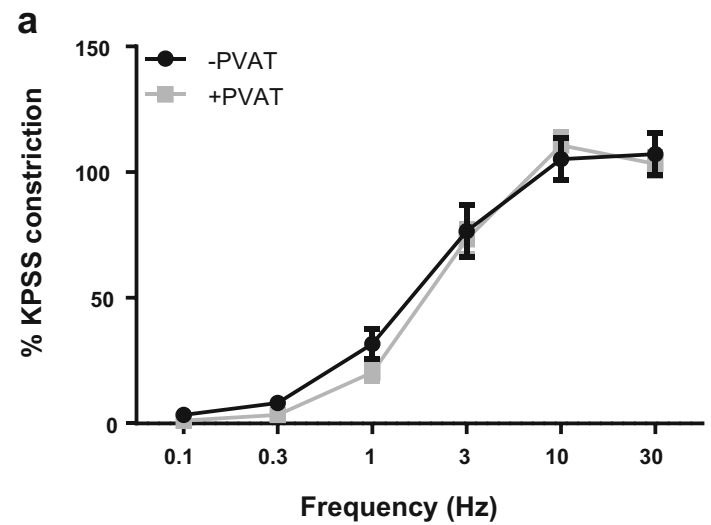

Fig. 3 PVAT anti-contractile dysfunction in obesity is recused with exercise. Vessels with and without PVAT from obese (a) and exercised obese (b) mice were subjected to EFS. Data shown are mean \pm SEM
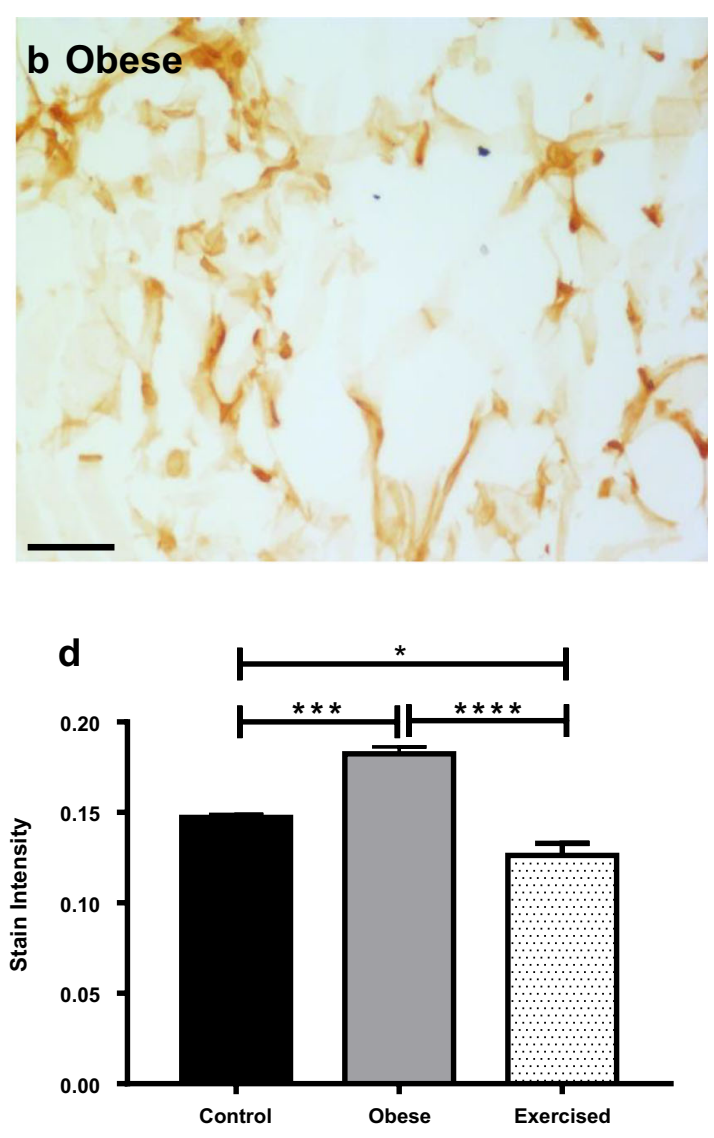

mean \pm SEM. Differences were tested using a one-way ANOVA $(n=5$ both groups, $* P<0.05, * * P<0.01, * * * * P<0.0001)$ (TNF $\alpha$ : tumour necrosis factor- $\alpha$ )

\section{$\beta_{3}$-Adrenoceptor Expression Is Downregulated in Obesity but Improved with Exercised}

In a previous study, we have indicated that PVAT function is mediated in part by $\beta_{3}$-adrenoceptors [37]; therefore, in an attempt to rescue PVAT dysfunction in obesity, the effects of the $\beta_{3}$-adrenoceptor agonist were tested. Following control

b

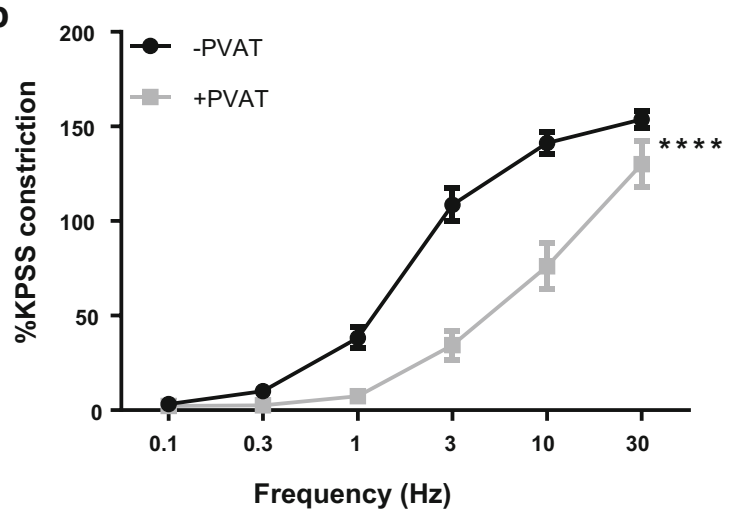

( $n=8$ for both, $* * * * P<0.0001)$ (EFS: electrical field stimulation; PVAT: perivascular adipose tissue) 
stimulations with EFS, \pm PVAT vessels from obese mice were incubated for $30 \mathrm{~min}$ with CL-316,243, before repeating the stimulus (Fig. 4e). CL-316,243 had no effect on either -PVAT or +PVAT vessels $(P>0.05, n=8)$, indicating that these receptors may be downregulated in obesity.

The expression of $\beta_{3}$-adrenoceptors was examined using immunohistochemistry in sections of mesenteric PVAT from control, obese, and exercised obese mice (Fig. $4 \mathrm{a}-\mathrm{d} ; n=5$ all groups). The intensity of staining in
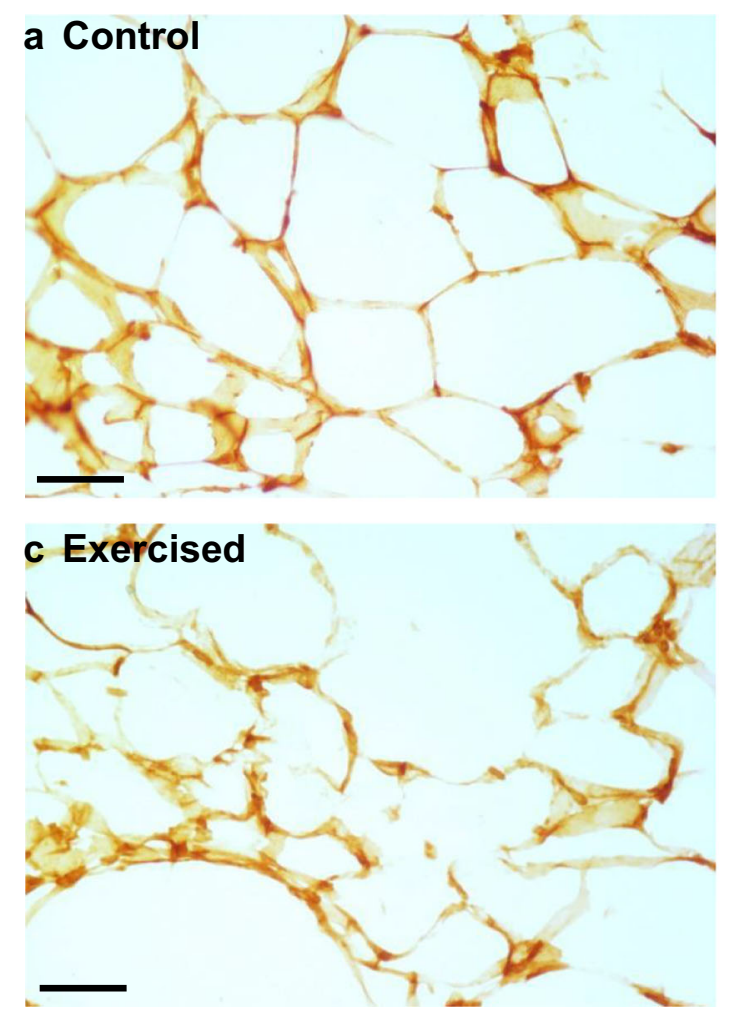

e

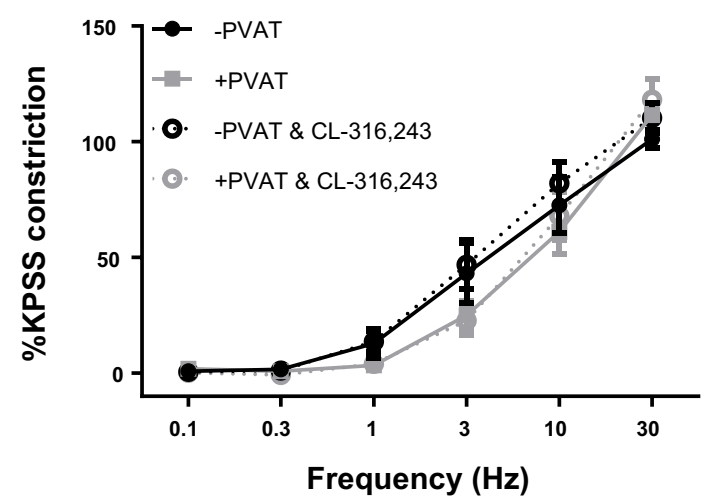

Fig. 4 Exercise in obesity upregulates $\beta_{3}$-adrenoceptor expression to restore anti-contractile function. Sections of mouse mesenteric PVAT from control mice (a), obese mice (b), and exercised obese mice (c) were stained for $\beta_{3}$-adrenoceptors. Scale bar represents $50 \mu \mathrm{m}$. Staining intensity of adipocyte membranes was quantified (d, $n=5$ all groups, $* P<0.05, * * P<0.01, * * * * P<0.0001$ ). Following control responses to EFS \pm PVAT vessels, obese vessels were incubated for $30 \mathrm{~min}$ with CL- the adipocyte membrane was quantified, and in obese mice, expression of the adrenoceptor was significantly reduced as compared with that in obese mice $(P<0.0001)$. In exercised obese mice, expression of $\beta_{3^{-}}$ adrenoceptors is significantly increased compared with obese mice $(P<0.01)$; however, expression is still significantly lower in exercised obese mice than in control mice $(P<0.05)$ (for positive and negative controls, see Supplementary Figure 4).
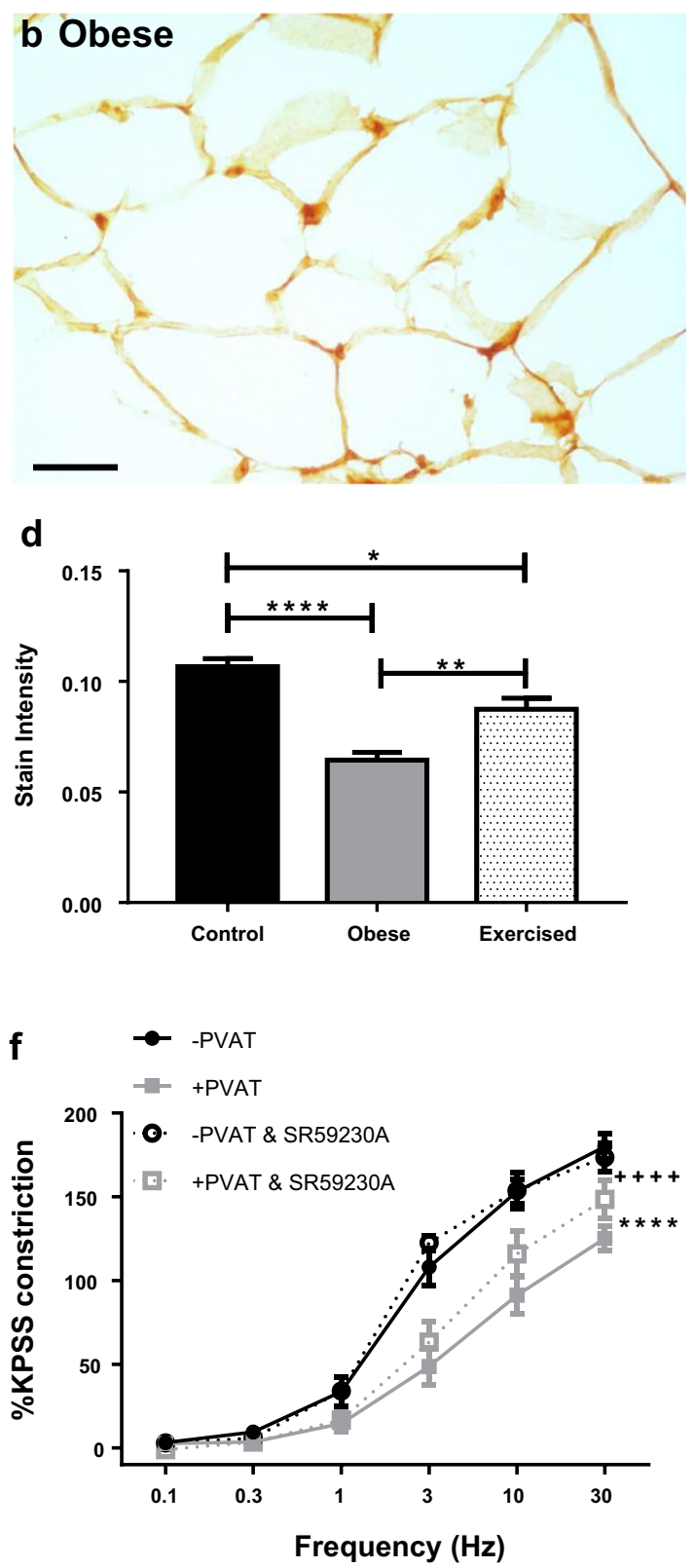

316,243 (e, $n=8, P>0.05)$, and exercised obese vessels were incubated with SR59230A (d, $n=8,-$ PVAT vs + PVAT $P<0.0001 * * * *,+$ PVAT vs +PVAT and SR59230A $P<0.0001 * * * *,-$ PVAT vs - PVAT and SR59230A $P>0.05,-$ PVAT vs +PVAT and SR59230A $P<0.0001^{* * * *}$ ). Data shown are mean \pm SEM (PVAT: perivascular adipose tissue) 
To determine if the increase in expression of $\beta_{3}$ adrenoceptors in exercise is sufficient to restore function, following the first EFS stimulation, \pm PVAT vessels from exercised obese mice were incubated with $\beta_{3}$-adrenoceptor antagonist SR59230A (Fig. 4f; $n=8$ ). Similar to previously reported data in control mice [37], SR59230A resulted in a significant reduction in the PVAT anti-contractile effect (-PVAT vs +PVAT $P<0.0001,-$ PVAT vs - PVAT and SR59230A $P>0.05,+$ PVAT vs + PVAT and SR59230A $P<0.0001$, - PVAT vs +PVAT and SR59230A $P<0.0001)$. These results indicate that exercise restored $\beta_{3}$-adrenoceptor-mediated PVAT function in obesity.

\section{OCT3 Expression Is Downregulated in Obesity and Is Reversed with Exercise}

We have previously demonstrated that the PVAT anti-contractile effect in health is mediated by a combination of $\beta_{3}$-adrenoceptormediated anti-contractile factor release, and NA uptake into adipocytes by OCT3 [37]. Therefore, using immunohistochemistry, we examined the expression of OCT3 in control, obese, and exercised obese PVAT ( $n=5$ all groups; Fig. $5 \mathrm{a}-\mathrm{d}$ ). The intensity of staining in the adipocyte membrane was quantified, and in obese mice, expression of OCT3 was significantly decreased compared with control mice $(P<0.05)$ and control mice ( $P<0.0001, n=5$ for all groups). However, in the exercised obese PVAT, OCT3 expression was significantly increased compared with both control and obese groups (control vs exercised obese $P<0.0001$, obese vs exercised obese $P<0.0001$ ) (for positive and negative controls, see Supplementary Figure 4).

PVAT denuded vessels with sections of exogenous PVAT suspended above were subjected to control EFS stimulations, before removing the exogenous PVAT and incubating with the OCT3 inhibitor corticosterone (Fig. 5e). Following 30-min incubation, the exogenous PVAT was re-suspended above the vessel, and the EFS protocol was repeated. Similar to previously published data in control mice [37], corticosterone induced a partial inhibition of the anti-contractile effect $(P<0.0001, n=8)$. Next, the exogenous PVAT was removed again and incubated with both corticosterone and SR59230A, and the restored anti-contractile effect in exercised obese mice was completely abolished $(P<0.0001, n=8)$, suggesting that the normal functioning of both $\beta_{3}$-adrenoceptors and OCT3 had been restored by exercise.

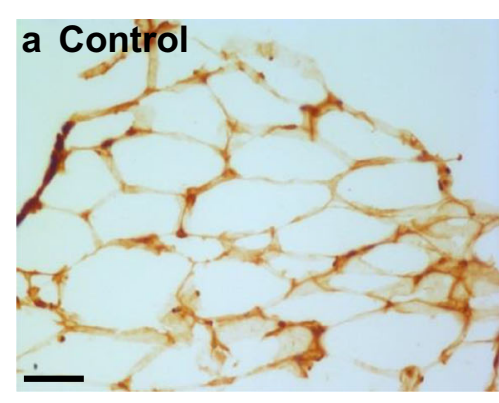

d

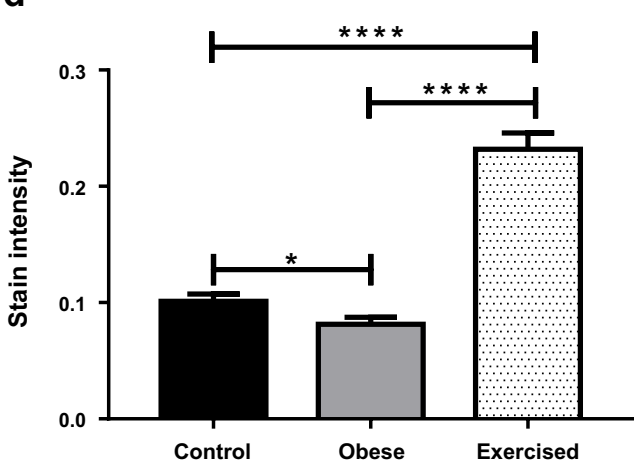

Fig. 5 Exercise upregulates OCT3, restoring NA uptake into adipocytes. Sections of mouse mesenteric PVAT from control mice (a), obese mice (b), and exercised obese mice (c) were stained for OCT3. Scale bar represents $50 \mu \mathrm{m}$. Staining intensity of adipocyte membranes was quantified (d, $n=5$ all groups, $* P<0.05, * * * * P<0.0001)$. e Following EFS, exercised obese vessels were incubated with corticosterone alone for $30 \mathrm{~min}$ and subjected to a second EFS protocol. Following this, vessels were incubated for a second time with
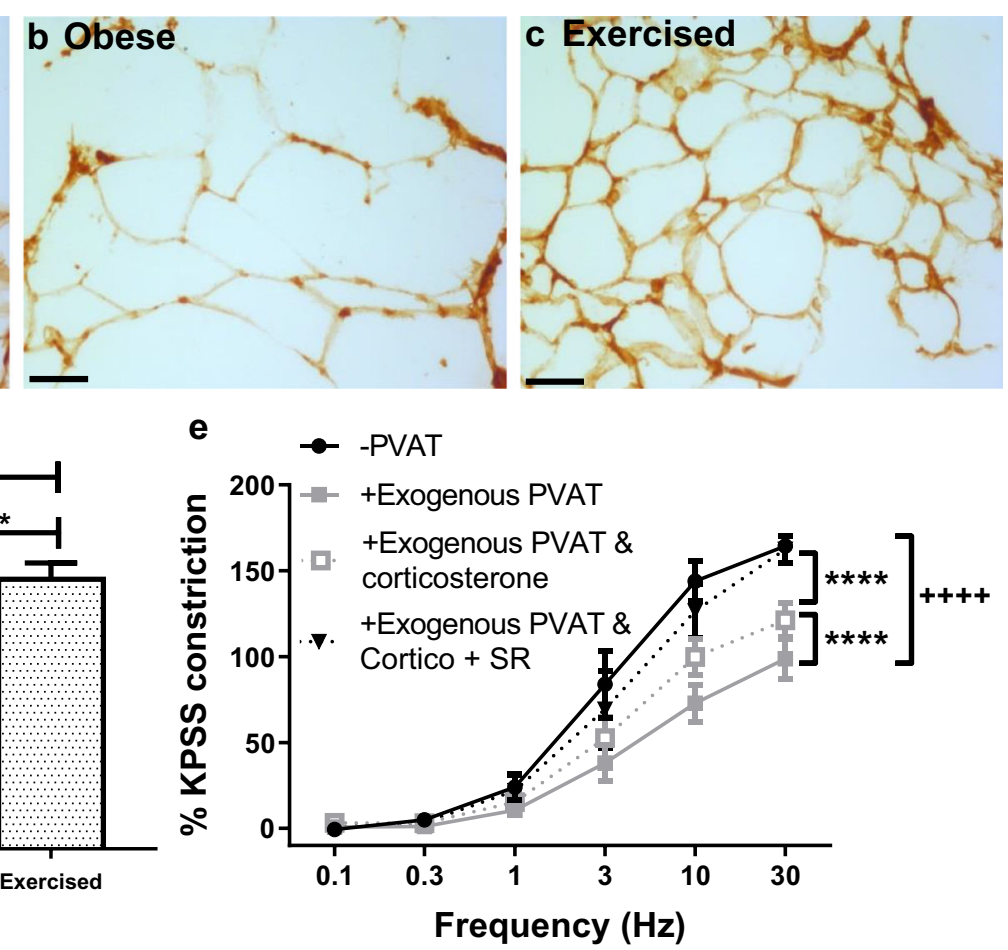

corticosterone plus SR59230A (SR) for $30 \mathrm{~min}$, before being stimulated with EFS for a final time $(n=8,-$ PVAT vs +exogenous PVAT $P<$ $0.0001^{++++},+$exogenous PVAT vs +exogenous PVAT and corticosterone $P<0.0001 * * * *,-$ PVAT vs +exogenous PVAT and corticosterone $P<$ $0.0001 * * * *$, +exogenous PVAT vs +exogenous PVAT and corticosterone + SR $P<0.0001 * * * *,-$ PVAT vs + exogenous PVAT and corticosterone + SR $P>0.05$ ). Data shown are mean \pm SEM (EFS: electrical field stimulation; NA: noradrenaline; OCT3: organic cation transporter 3 ) 


\section{Adiponectin Is a Vasodilator in Exercised Obese Arteries But Not in Obese Arteries}

Previously, we have reported that adiponectin is the anticontractile factor released upon $\beta_{3}$-adrenoceptor activation [37]; therefore, we measured the secretion of adiponectin from obese PVAT compared with secretion from healthy control PVAT. PVAT was collected from the mesenteric beds of control and obese mice and stimulated at $10 \mathrm{~Hz}$ for $4 \mathrm{~s}$. The surrounding supernatant was collected and adiponectin concentration was quantified using an ELISA. The concentration of adiponectin secreted from the obese PVAT was significantly reduced as compared with the healthy control (Fig. $6 \mathrm{a} ; n=12$ both groups, $P<0.0001$ ).

An ELISA kit was used to measure plasma adiponectin (Fig. 6b) (control and obese groups $n=22$, exercised obese $n=20$ ). Plasma adiponectin was significantly increased in obesity and was reduced back to control levels with exercise (control vs obese $P<0.01$, obese vs exercised obese $P<0.01$, control vs exercised obese $P>0.05$ ).

To determine if adiponectin presents a viable target for treating the vascular complications of obesity, the effects of

a

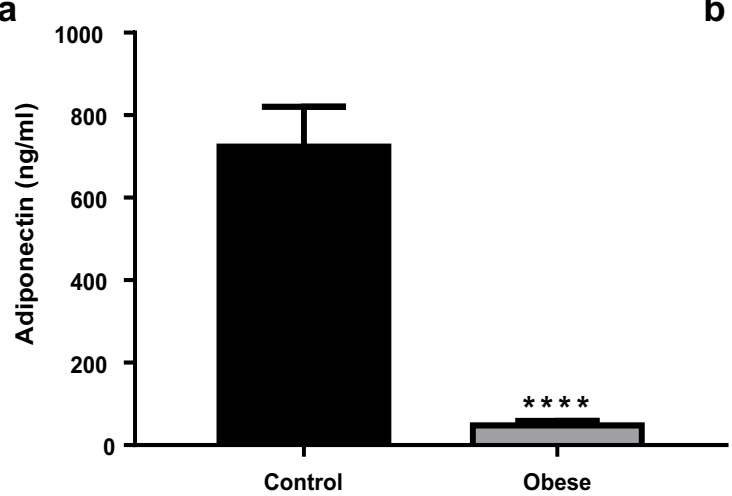

C

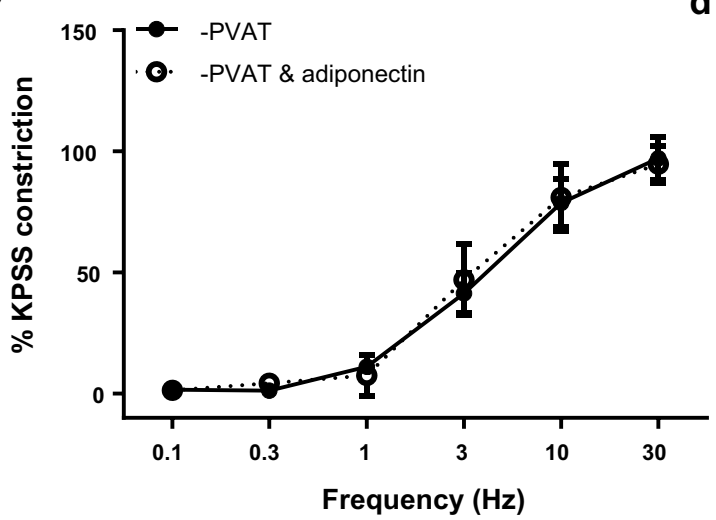

Fig. 6 Adiponectin secretion in obesity is reduced and its vasodilator function is lost. a Mesenteric PVAT from control and obese mice was collected and adiponectin secretion per $100 \mathrm{mg}$ was measured $(n=12$ both groups, $P<0.0001 * * * *)$. Following sacrifice, blood was collected and centrifuged to separate plasma. Plasma concentrations of adiponectin (b) were measured using an ELISA kit (control $n=22$, obese $n=22$,

d globular adiponectin were tested in obese and exercised obese mice. Following control stimulations with EFS, -PVAT vessels were given $15 \mathrm{~min}$ to recover before incubating with exogenous adiponectin for a further $5 \mathrm{~min}$. In obese vessels, exogenous application of adiponectin no longer elicits a vasodilator effect (Fig. 6c; $P>0.05, n=4$ ). However, in exercised obese mice, adiponectin did cause a vasodilation (Fig. 6d; $P<0.0001, n=$ $4)$, indicating that the impaired vasodilator function of adiponectin in obesity has been restored by exercise.

\section{Discussion}

This study has for the first time investigated the effects of autonomic dysfunction on the PVAT effect in obesity and the potential for exercise in restoring PVAT function in resistance arteries. The main findings of this study were (1) in obesity, PVAT becomes inflamed, and this inflammation is reversed with exercise; (2) the sympathetic nerve-mediated PVAT anti-contractile effect is lost in obesity, but can be rescued using exercise; (3) reversal of PVAT dysfunction in obesity using exercise is accompanied by normalised blood
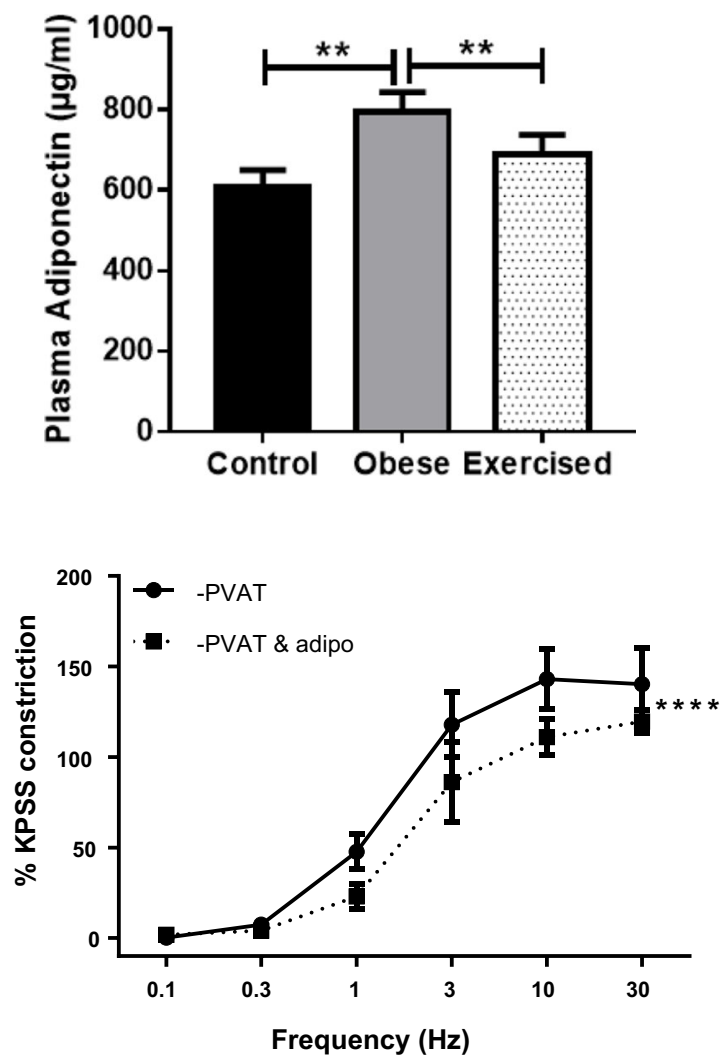

exercised $\left.n=20, P<0.01^{* *}\right)$. Following the control EFS protocol, PVAT-denuded vessels from obese (c) and exercised obese (d) were allowed $15 \mathrm{~min}$ to recover before incubating with recombinant globular mouse adiponectin for $15 \mathrm{~min}$ and repeating the stimulus $(n=4$ for both, $P<0.0001^{* * * *}$ ). Data shown are mean \pm SEM (EFS: electrical field stimulation; PVAT: perivascular adipose tissue) 
pressure, blood glucose, and plasma insulin, independent of weight loss; (4) expression of $\beta_{3}$-adrenoceptors and OCT3 are downregulated in obesity, and activation of $\beta_{3}$-adrenoceptors cannot restore function; (5) adiponectin secretion from mesenteric PVAT is reduced in obesity; and (6) the vasodilator function of adiponectin is lost in obesity but can be rescued using exercise.

We found that 10-12 weeks of high fat feeding induced increased adiposity, hypertension, and hyperglycaemia. Plasma insulin was also increased threefold, which, in combination with hyperglycaemia, would suggest that these mice may have type II diabetes, although glucose tolerance testing is required to confirm. In humans, metabolic syndrome is defined by a combination of at least three out of five conditions: abdominal obesity, hypertension, type-II diabetes, hypertriglyceridemia, and hypercholesterolemia [41]. Therefore, these results are indicative of metabolic syndrome. Consistent with other exercise studies, we have demonstrated that exercise relieves the vascular and metabolic complications of obesity, i.e., hypertension, hyperglycaemia, and hyperinsulinemia [42-44]. These findings were independent of weight loss, which fits with the "fat but fit" hypothesis, proposing that cardiorespiratory fitness may be a more important determinant of mortality than weight [45]. Hypertension and type II diabetes are major risk factors in CVD and contribute to the short life expectancy of obese patients; therefore, treatment of these vascular diseases using this exercise model may extend the life expectancy of obese patients.

We reported a reduced level of circulating NA in our obese mouse model, and a similar reduction in plasma NA in obesity has been reported in human patients [46]. However, measurements of plasma NA and urinary metabolites are only indicative of autonomic dysfunction and not nerve activity, as these measurements do not take into account dysfunction that may be occurring downstream, e.g., NA uptake into the periphery [47]. Therefore, reduced circulating NA does not mean reduced nerve activity and only confirms dysfunction [46]. In obesity, it is widely accepted that sympathetic nerves become overactive in both rodents and humans $[8,9,48]$. Indirect recordings such as plasma NA or responses to autonomic blockade are often used for a rough guide on changes in autonomic function; however, direct recordings of sympathetic nerve activity would provide a more accurate investigation of autonomic over-activity in our model of obesity [49]. However, currently, there are no commercially available telemeter devices to measure sympathetic nerve activity in conscious mice. Direct recordings can be taken in anaesthetised mice, but these preparations raise concerns regarding the effects of anaesthetic on sympathetic nerve activity and arterial blood pressure, which is intimately linked to sympathetic nerve activity and is greatly reduced under anaesthesia [50]. There has been some success by Hamza and Hall [51] in developing an experimental method for direct recordings of renal sympathetic nerve activity in conscious mice; however, the viability of nerve recordings decreased rapidly in the days following surgery, making this method unsuitable in its current state for recording nerve activity before and after high fat feeding.

Activation of $\beta_{3}$-adrenoceptors using an agonist did not rescue loss of function, indicating either dysfunction or downregulation of the receptor. There are no agonists available for OCT3; therefore, we were unable to determine if pharmacological manipulation of this transporter could restore function. In this study, we have indicated a downregulation of both $\beta_{3^{-}}$ adrenoceptors and OCT3 using immunohistochemistry, which is not a quantitative measure and is therefore a limitation of this study. In heart failure, over-activity of sympathetic nerves results in desensitisation and internalisation of $\beta_{3}$-adrenoceptors [10]. In future studies, we aim to demonstrate using western blots and quantitative PCR that a similar process is occurring in obese adipose tissue, resulting in a reduction in expression of $\beta_{3}$-adrenoceptors and OCT3. It has been suggested that $\beta_{3^{-}}$ adrenoceptors are a potential target for the treatment of hypertension in obesity, as agonists have been shown to be hypotensive in healthy canines and rodents $[52,53]$; however, reduced expressions of $\beta_{3}$-adrenoceptors in obesity make the application of an agonist redundant. Reduced expression of $\beta_{3^{-}}$ adrenoceptors in obesity has been shown in a number of obese mouse models [54]; however, this is the first study to report a change in expression of OCT3 in obesity.

The reduced expression of $\beta_{3}$-adrenoceptors in obesity results in a reduction in adiponectin secretion as demonstrated in this study using an ELISA. Reduced secretion of the vasodilator adiponectin will contribute to increases in arterial tone and blood pressure. Paradoxically, we found plasma adiponectin levels to be elevated in our obese mice. Studies have shown that adiponectin clearance in obesity is impaired [57]; therefore, it is possible that this has resulted in an accumulation of adiponectin in the plasma of our mice. Typically, plasma adiponectin is accepted as reduced in obesity $[11,55,56]$. The obese model used here is a relatively acute model of obesity. It is possible that this accumulation of adiponectin is an early compensatory mechanism in obesity in response to reduced secretion, and levels will decline with chronic obesity. Nonetheless, with exercise, plasma adiponectin levels were returned to normal, indicating a restorative effect of exercise on adiponectin secretion and clearance.

To determine if administration of adiponectin would be useful in obesity, we applied exogenous adiponectin to obese arteries. However, the vasodilator effects of adiponectin were absent. This may suggest that increased plasma adiponectin may have resulted in desensitisation of receptors. In addition, adiponectin causes vasodilation via mechanisms dependent upon adenosine monophosphate-activated protein kinase (AMPK) $[58,59]$. In obesity, phosphorylation of AMPK is reduced; supressing AMPK activity [60,61]. It is possible that the lack of adiponectin function in obesity may be due to changes in AMPK activity in the vascular smooth muscle and 
endothelial cells. However, in this study, we were able to restore the vasodilator effects of adiponectin in obesity using exercise.

This is the first study to demonstrate a restoration of the PVAT anti-contractile effect in resistance arteries in obesity using exercise. Moreover, these findings were independent of weight loss. One of the beneficial effects in PVAT of exercise is reduced inflammation. There is a clear reduction in the expression of TNF $\alpha$, an important inflammatory marker [22] in exercised obese PVAT. This will therefore reduce the damage caused to PVAT by inflammation. The results of the TNF $\alpha$ expression studies are consistent with previous studies in our laboratory, whereby bariatric surgery in obese patients restored anti-contractile function in PVAT and reduced inflammation in PVAT, whilst patients were still in the obese body mass index (BMI) range [32].

We are the first to demonstrate that expression of $\beta_{3^{-}}$ adrenoceptors and OCT3 are increased by exercise. Expression levels of OCT 3 have been returned to control levels, whereas expression of $\beta_{3}$-adrenoceptors is still below normal. However, the efficacy of the $\beta_{3}$-adrenoceptor antagonist in reducing the anti-contractile effect alone, and abolishing the anticontractile effect in combination with the OCT3 inhibitor would suggest that the expression of $\beta_{3}$-adrenoceptors has increased enough to restore the healthy PVAT anti-contractile mechanism. Therefore, healthy sympathetic activity, i.e., exercise, has restored PVAT's ability to release an anti-contractile factor upon $\beta_{3}$-adrenoceptor activation, and the ability to transport NA into adipocytes via OCT3, preventing the NA from reaching the blood vessel and eliciting contraction.

Many studies have indicated that exercise can induce "beiging" of white adipose tissue [62-65]. This process, by which white adipocytes can be stimulated to differentiate into an intermediate between white and brown adipocyte, results in "beige" or "brite" adipocytes which can participate in thermogenesis, making it metabolically beneficial $[63,66]$. The degree of beiging is dependent on the duration and type of exercise [67, 68], and it is possible that this process has been induced in the exercise model used here. Furthermore, both $\beta_{3}$-adrenoceptors [69-72] and OCT3 [73] have been indicated in beiging. In future studies, we will aim to investigate the potential role of beiging in the beneficial effects of our exercise model.

Dysfunction of the sympathetic nervous system in obese PVAT results in a loss of the PVAT anti-contractile effect, which may be contributing to the development of hypertension and type II diabetes. The over-activity of sympathetic nerves in obesity causes downregulation of $\beta_{3}$-adrenoceptors and OCT3, resulting in a loss of PVAT function. Moreover, obese arteries are no longer responsive to adiponectin. Healthy sympathetic activity, i.e., exercise, restored the normal PVAT anti-contractile mechanism in obesity, independent of weight loss. Exercise reduced inflammation of PVAT and increased expression of $\beta_{3}$-adrenoceptors and
OCT3 to restore function. Moreover, the vasodilator function of adiponectin was restored. As a result of repaired PVAT function, the vascular complications of obesity, hypertension, and type II diabetes were reversed, indicating exercise as an effective treatment for obesity-related illnesses, highlighting the importance of exercise as a first line of treatment in the vascular complications of obesity.

Supplementary Information The online version contains supplementary material available at https://doi.org/10.1007/s10557-020-07136-0.

Acknowledgements We thank the Biological Services Facility at the University of Manchester for their assistance with animal work and Dr. Elizabeth Cartwright for allowing us to conduct these studies under her home office licence.

Author Contributions S.N.S., S.B.W., J.O., and A.M.H. conception and design of research; S.N.S., L.K.T., and R.G.A. performed experiments; S.N.S., L.K.T, and R.G.A. analysed data; S.N.S., S.B.W., J.O., and A.M.H. interpreted results of experiments; S.N.S. prepared figures; S.N.S. drafted manuscript; and S.N.S., S.B.W., and A.M.H. edited and revised manuscript. All authors approved final version of manuscript.

Funding This work was supported by the British Heart Foundation (FS/ 13/56/30645, FS/16/58/32734 and PG/16/52/32229).

\section{Compliance with Ethical Standards}

Conflict of Interest The authors declare that they have no conflict of interest.

Ethics Approval All animal experiments were performed with approval from the University of Manchester ethics committee.

Open Access This article is licensed under a Creative Commons Attribution 4.0 International License, which permits use, sharing, adaptation, distribution and reproduction in any medium or format, as long as you give appropriate credit to the original author(s) and the source, provide a link to the Creative Commons licence, and indicate if changes were made. The images or other third party material in this article are included in the article's Creative Commons licence, unless indicated otherwise in a credit line to the material. If material is not included in the article's Creative Commons licence and your intended use is not permitted by statutory regulation or exceeds the permitted use, you will need to obtain permission directly from the copyright holder. To view a copy of this licence, visit http://creativecommons.org/licenses/by/4.0/.

\section{References}

1. Aghamohammadzadeh R, Heagerty AM. Obesity-related hypertension: epidemiology, pathophysiology, treatments, and the contribution of perivascular adipose tissue. Ann Med. 2012;44(Suppl 1): S74-84.

2. Bjorndal B, Burri L, Staalesen V, Skorve J, Berge RK. Different adipose depots: their role in the development of metabolic syndrome and mitochondrial response to hypolipidemic agents. J Obes. 2011;2011:490650. 
3. Soltis EE, Cassis LA. Influence of perivascular adipose tissue on rat aortic smooth muscle responsiveness. Clin Exp Hypertens A. 1991;13:277-96.

4. Saxton SN, Ryding KE, Aldous RG, Withers SB, Ohanian J, Heagerty AM. Role of sympathetic nerves and adipocyte catecholamine uptake in the vasorelaxant function of perivascular adipose tissue. Arterioscler Thromb Vasc Biol. 2018;38:880-91.

5. Lynch FM, Withers SB, Yao Z, Werner ME, Edwards G, Weston $\mathrm{AH}$, et al. Perivascular adipose tissue-derived adiponectin activates $\mathrm{BK}(\mathrm{Ca})$ channels to induce anticontractile responses. Am J Physiol Heart Circ Physiol. 2013;304:H786-95.

6. Greenstein AS, Khavandi K, Withers SB, Sonoyama K, Clancy O, Jeziorska M, et al. Local inflammation and hypoxia abolish the protective anticontractile properties of perivascular fat in obese patients. Circulation. 2009;119:1661-70.

7. Saxton SN, Clark BJ, Withers SB, Eringa EC, Heagerty AM. Mechanistic links between obesity, diabetes, and blood pressure: role of perivascular adipose tissue. Physiol Rev. 2019;99:1701-63.

8. Smith MM, Minson CT. Obesity and adipokines: effects on sympathetic overactivity. J Physiol. 2012;590:1787-801.

9. Manolis AJ, Poulimenos LE, Kallistratos MS, Gavras I, Gavras H. Sympathetic overactivity in hypertension and cardiovascular disease. Curr Vasc Pharmacol. 2014;12:4-15.

10. Post SR, Hammond HK, Insel PA. Beta-adrenergic receptors and receptor signaling in heart failure. Annu Rev Pharmacol Toxicol. 1999;39:343-60.

11. Arita Y, Kihara S, Ouchi N, Takahashi M, Maeda K, Miyagawa J, et al. Paradoxical decrease of an adipose-specific protein, adiponectin, in obesity. Biochem Biophys Res Commun. 1999;257:79-83.

12. Imatoh $\mathrm{T}$, Miyazaki M, Momose $\mathrm{Y}$, Tanihara S, Une H. Adiponectin levels associated with the development of hypertension: a prospective study. Hypertens Res. 2008;31:229-33.

13. Nayak S, Soon SQ, Kunjal R, Ramadoo R, Baptiste O, Persad J, et al. Relationship between adiponectin, inflammatory markers and obesity in type 2 diabetic and non-diabetic Trinidadians. Arch Physiol Biochem. 2009;115:28-33.

14. Kabon B, Nagele A, Reddy D, Eagon C, Fleshman JW, Sessler DI, et al. Obesity decreases perioperative tissue oxygenation. Anesthesiology. 2004;100:274-80.

15. de Ferranti S, Mozaffarian D. The perfect storm: obesity, adipocyte dysfunction, and metabolic consequences. Clin Chem. 2008;54: 945-55.

16. Withers SB, Agabiti-Rosei C, Livingstone DM, Little MC, Aslam $\mathrm{R}$, Malik RA, et al. Macrophage activation is responsible for loss of anticontractile function in inflamed perivascular fat. Arterioscler Thromb Vasc Biol. 2011;31:908-13.

17. Saxton SN, Heagerty AM, Withers SB. Perivascular adipose tissue: an immune cell metropolis. Exp Physiol. 2020;105:1440-3.

18. Aghamohammadzadeh R, Unwin RD, Greenstein AS, Heagerty AM. Effects of obesity on perivascular adipose tissue vasorelaxant function: nitric oxide, inflammation and elevated systemic blood pressure. J Vasc Res. 2015;52:299-305.

19. Yokota T, Oritani K, Takahashi I, Ishikawa J, Matsuyama A, Ouchi $\mathrm{N}$, et al. Adiponectin, a new member of the family of soluble defense collagens, negatively regulates the growth of myelomonocytic progenitors and the functions of macrophages. Blood. 2000;96:1723-32.

20. Ouchi N, Kihara S, Arita Y, Maeda K, Kuriyama H, Okamoto Y, et al. Novel modulator for endothelial adhesion molecules: adipocyte-derived plasma protein adiponectin. Circulation. 1999; 100:2473-6.

21. Hotamisligil GS, Murray DL, Choy LN, Spiegelman BM. Tumor necrosis factor alpha inhibits signaling from the insulin receptor. Proc Natl Acad Sci U S A. 1994;91:4854-8.

22. Hotamisligil GS, Spiegelman BM. Tumor necrosis factor alpha: a key component of the obesity-diabetes link. Diabetes. 1994;43: $1271-8$.
23. Samaan MC, Marcinko K, Sikkema S, Fullerton MD, Ziafazeli T, Khan MI, et al. Endurance interval training in obese mice reduces muscle inflammation and macrophage content independently of weight loss. Physiol Rep. 2014;2:e12012.

24. Bradley RL, Jeon JY, Liu FF, Maratos-Flier E. Voluntary exercise improves insulin sensitivity and adipose tissue inflammation in diet-induced obese mice. Am J Physiol Endocrinol Metab. 2008;295:E586-94.

25. Kawanishi N, Yano H, Yokogawa Y, Suzuki K. Exercise training inhibits inflammation in adipose tissue via both suppression of macrophage infiltration and acceleration of phenotypic switching from M1 to M2 macrophages in high-fat-diet-induced obese mice. Exerc Immunol Rev. 2010;16:105-18.

26. Saxton SN, Withers SB, Heagerty AM. Emerging roles of sympathetic nerves and inflammation in perivascular adipose tissue. Cardiovasc Drugs Ther. 2019;33:245-59.

27. Khadir A, Kavalakatt S, Cherian P, Warsame S, Abubaker JA, Dehbi M, et al. Physical exercise enhanced heat shock protein 60 expression and attenuated inflammation in the adipose tissue of human diabetic obese. Front Endocrinol (Lausanne). 2018;9:16.

28. Araujo HN, Victorio JA, Valgas da Silva CP, Sponton ACS, Vettorazzi JF, de Moraes C, et al. Anti-contractile effects of perivascular adipose tissue in thoracic aorta from rats fed a highfat diet: role of aerobic exercise training. Clin Exp Pharmacol Physiol. 2018;45:293-302.

29. Meziat C, Boulghobra D, Strock E, Battault S, Bornard I, Walther $\mathrm{G}$, et al. Exercise training restores eNOS activation in the perivascular adipose tissue of obese rats: impact on vascular function. Nitric Oxide. 2019;86:63-7.

30. Sousa AS, Sponton ACS, Trifone CB, Delbin MA. Aerobic exercise training prevents perivascular adipose tissue-induced endothelial dysfunction in thoracic aorta of obese mice. Front Physiol. 2019;10:1009.

31. DeVallance E, Branyan KW, Lemaster KC, Anderson R, Marshall $\mathrm{KL}$, Olfert IM, et al. Exercise training prevents the perivascular adipose tissue-induced aortic dysfunction with metabolic syndrome. Redox Biol. 2019;26:101285.

32. Aghamohammadzadeh R, Greenstein AS, Yadav R, Jeziorska M, Hama S, Soltani F, et al. Effects of bariatric surgery on human small artery function: evidence for reduction in perivascular adipocyte inflammation, and the restoration of normal anticontractile activity despite persistent obesity. J Am Coll Cardiol. 2013;62:128-35.

33. Bussey CE, Withers SB, Aldous RG, Edwards G, Heagerty AM. Obesity-related perivascular adipose tissue damage is reversed by sustained weight loss in the rat. Arterioscler Thromb Vasc Biol. 2016;36:1377-85.

34. Xia N, Weisenburger S, Koch E, Burkart M, Reifenberg G, Forstermann U, et al. Restoration of perivascular adipose tissue function in diet-induced obese mice without changing bodyweight. Br J Pharmacol. 2017;174:3443-53.

35. Hariri N, Thibault L. High-fat diet-induced obesity in animal models. Nutr Res Rev. 2010;23:270-99.

36. D'Souza A, Bucchi A, Johnsen AB, Logantha SJ, Monfredi O, Yanni J, et al. Exercise training reduces resting heart rate via downregulation of the funny channel HCN4. Nat Commun. 2014;5:3775.

37. Saxton SN, Ryding KE, Aldous RG, Withers SB, Ohanian J, Heagerty AM. Role of Sympathetic Nerves and Adipocyte Catecholamine Uptake in the Vasorelaxant Function of Perivascular Adipose Tissue. Arterioscler Thromb Vasc Biol. 2018;38: 880-891.

38. Mulvany MJ, Halpern W. Contractile properties of small arterial resistance vessels in spontaneously hypertensive and normotensive rats. Circ Res. 1977;41:19-26.

39. Altman DG, Bland JM. Statistics notes. Units of analysis. Bmj. 1997;314:1874. 
40. Gao YJ, Lu C, Su LY, Sharma AM, Lee RM. Modulation of vascular function by perivascular adipose tissue: the role of endothelium and hydrogen peroxide. Br J Pharmacol. 2007;151:323-31.

41. Bauduceau B, Vachey E, Mayaudon H, Burnat P, Dupuy O, Garcia $\mathrm{C}$, et al. Should we have more definitions of metabolic syndrome or simply take waist measurement? Diabetes Metab. 2007;33:333-9.

42. Abdelaal AA, Mohamad MA. Obesity indices and haemodynamic response to exercise in obese diabetic hypertensive patients: randomized controlled trial. Obes Res Clin Pract. 2015;9:475-86.

43. Reisin E, Jack AV. Obesity and hypertension: mechanisms, cardiorenal consequences, and therapeutic approaches. Med Clin North Am. 2009;93:733-51.

44. Riddell MC, Miadovnik L, Simms M, Li B, Zisser H. Advances in exercise, physical activity, and diabetes mellitus. Diabetes Technol Ther. 2013;15(Suppl 1):S96-106.

45. Barry VW, Baruth M, Beets MW, Durstine JL, Liu J, Blair SN. Fitness vs. fatness on all-cause mortality: a meta-analysis. Prog Cardiovasc Dis. 2014;56:382-90.

46. Astrup A, Andersen T, Christensen NJ, Bulow J, Madsen J, Breum $\mathrm{L}$, et al. Impaired glucose-induced thermogenesis and arterial norepinephrine response persist after weight reduction in obese humans. Am J Clin Nutr. 1990;51:331-7.

47. Grassi G, Seravalle G, Dell'oro R. Sympathetic activation in obesity: a noninnocent bystander. In: Hypertension United States, vol. 56; 2010. p. 338-40.

48. Schwartz JH, Young JB, Landsberg L. Effect of dietary fat on sympathetic nervous system activity in the rat. J Clin Invest. 1983;72:361-70.

49. Young CN, Davisson RL. In vivo assessment of neurocardiovascular regulation in the mouse: principles, progress, and prospects. Am J Physiol Heart Circ Physiol. 2011;301:H654-62.

50. Kass DA, Hare JM, Georgakopoulos D. Murine cardiac function: a cautionary tail. Circ Res. 1998;82:519-22.

51. Hamza SM, Hall JE. Direct recording of renal sympathetic nerve activity in unrestrained, conscious mice. Hypertension. 2012;60:856-64.

52. Ursino MG, Vasina V, Raschi E, Crema F, De Ponti F. The beta3adrenoceptor as a therapeutic target: current perspectives. Pharmacol Res. 2009;59:221-34.

53. Shen YT, Cervoni P, Claus T, Vatner SF. Differences in beta 3adrenergic receptor cardiovascular regulation in conscious primates, rats and dogs. J Pharmacol Exp Ther. 1996;278:1435-43.

54. Collins S, Daniel KW, Rohlfs EM. Depressed expression of adipocyte beta-adrenergic receptors is a common feature of congenital and diet-induced obesity in rodents. Int J Obes Relat Metab Disord. 1999:23:669-77.

55. Meijer RI, Bakker W, Alta CL, Sipkema P, Yudkin JS, Viollet B, et al. Perivascular adipose tissue control of insulin-induced vasoreactivity in muscle is impaired in $\mathrm{db} / \mathrm{db}$ mice. Diabetes. 2013;62:590-8.

56. De Rosa A, Monaco ML, Capasso M, Forestieri P, Pilone V, Nardelli C, et al. Adiponectin oligomers as potential indicators of adipose tissue improvement in obese subjects. Eur J Endocrinol. 2013;169:37-43.

57. Halberg N, Schraw TD, Wang ZV, Kim JY, Yi J, Hamilton MP, et al. Systemic fate of the adipocyte-derived factor adiponectin. Diabetes. 2009;58:1961-70.

58. Steinberg GR, Kemp BE. AMPK in health and disease. Physiol Rev. 2009;89:1025-78.

59. Foller M, Jaumann M, Dettling J, Saxena A, Pakladok T, Munoz C, et al. AMP-activated protein kinase in BK-channel regulation and protection against hearing loss following acoustic overstimulation. FASEB J. 2012;26:4243-53.

60. Pang J, Choi Y, Park T. Ilex paraguariensis extract ameliorates obesity induced by high-fat diet: potential role of AMPK in the visceral adipose tissue. Arch Biochem Biophys. 2008;476:178-85.

61. Mortensen B, Poulsen P, Wegner L, Stender-Petersen KL, RibelMadsen R, Friedrichsen M, et al. Genetic and metabolic effects on skeletal muscle AMPK in young and older twins. Am J Physiol Endocrinol Metab. 2009;297:E956-64.

62. Takaoka M, Nagata D, Kihara S, Shimomura I, Kimura Y, Tabata $\mathrm{Y}$, et al. Periadventitial adipose tissue plays a critical role in vascular remodeling. Circ Res. 2009;105:906-11.

63. Himms-Hagen J, Melnyk A, Zingaretti MC, Ceresi E, Barbatelli G, Cinti S. Multilocular fat cells in WAT of CL-316243-treated rats derive directly from white adipocytes. Am J Physiol Cell Physiol. 2000;279:C670-81.

64. Cousin B, Cinti S, Morroni M, Raimbault S, Ricquier D, Penicaud $\mathrm{L}$, et al. Occurrence of brown adipocytes in rat white adipose tissue: molecular and morphological characterization. J Cell Sci. 1992;103(Pt 4):931-42.

65. Guerra C, Koza RA, Yamashita H, Walsh K, Kozak LP. Emergence of brown adipocytes in white fat in mice is under genetic control. Effects on body weight and adiposity. J Clin Invest. 1998;102:412-20.

66. Warner A, Kjellstedt A, Carreras A, Bottcher G, Peng XR, Seale P, et al. Activation of beta3-adrenoceptors increases in vivo free fatty acid uptake and utilization in brown but not white fat depots in high-fat-fed rats. Am J Physiol Endocrinol Metab. 2016;311: E901-e910.

67. Stanford KI, Middelbeek RJ, Townsend KL, Lee MY, Takahashi $\mathrm{H}$, So K, et al. A novel role for subcutaneous adipose tissue in exercise-induced improvements in glucose homeostasis. Diabetes. 2015;64:2002-14.

68. Dewal RS, Stanford KI. Effects of exercise on brown and beige adipocytes. Biochim Biophys Acta Mol Cell Biol Lipids. 2019;1864:71-78.

69. Park JW, Jung KH, Lee JH, Quach CH, Moon SH, Cho YS, et al. 18F-FDG PET/CT monitoring of beta3 agonist-stimulated brown adipocyte recruitment in white adipose tissue. J Nucl Med. 2015;56:153-8.

70. Merlin J, Sato M, Chia LY, Fahey R, Pakzad M, Nowell CJ, et al. Rosiglitazone and a beta3-Adrenoceptor agonist are both required for functional browning of white adipocytes in culture. Front Endocrinol (Lausanne). 2018;9:249.

71. Wang S, Wang X, Ye Z, Xu C, Zhang M, Ruan B, et al. Curcumin promotes browning of white adipose tissue in a norepinephrinedependent way. Biochem Biophys Res Commun. 2015;466:247-53.

72. Jimenez M, Barbatelli G, Allevi R, Cinti S, Seydoux J, Giacobino $\mathrm{JP}$, et al. Beta 3-adrenoceptor knockout in C57BL/6J mice depresses the occurrence of brown adipocytes in white fat. Eur $\mathrm{J}$ Biochem. 2003;270:699-705.

73. Song W, Luo Q, Zhang Y, Zhou L, Liu Y, Ma Z, et al. Organic cation transporter 3 (Oct3) is a distinct catecholamines clearance route in adipocytes mediating the beiging of white adipose tissue. PLoS Biol. 2019;17:e2006571.

Publisher's Note Springer Nature remains neutral with regard to jurisdictional claims in published maps and institutional affiliations. 